\title{
Area contact networks and the spatio-temporal spread of infectious salmon
}

$$
\text { anemia virus (ISAV) in Chile }
$$

(1)

(1)

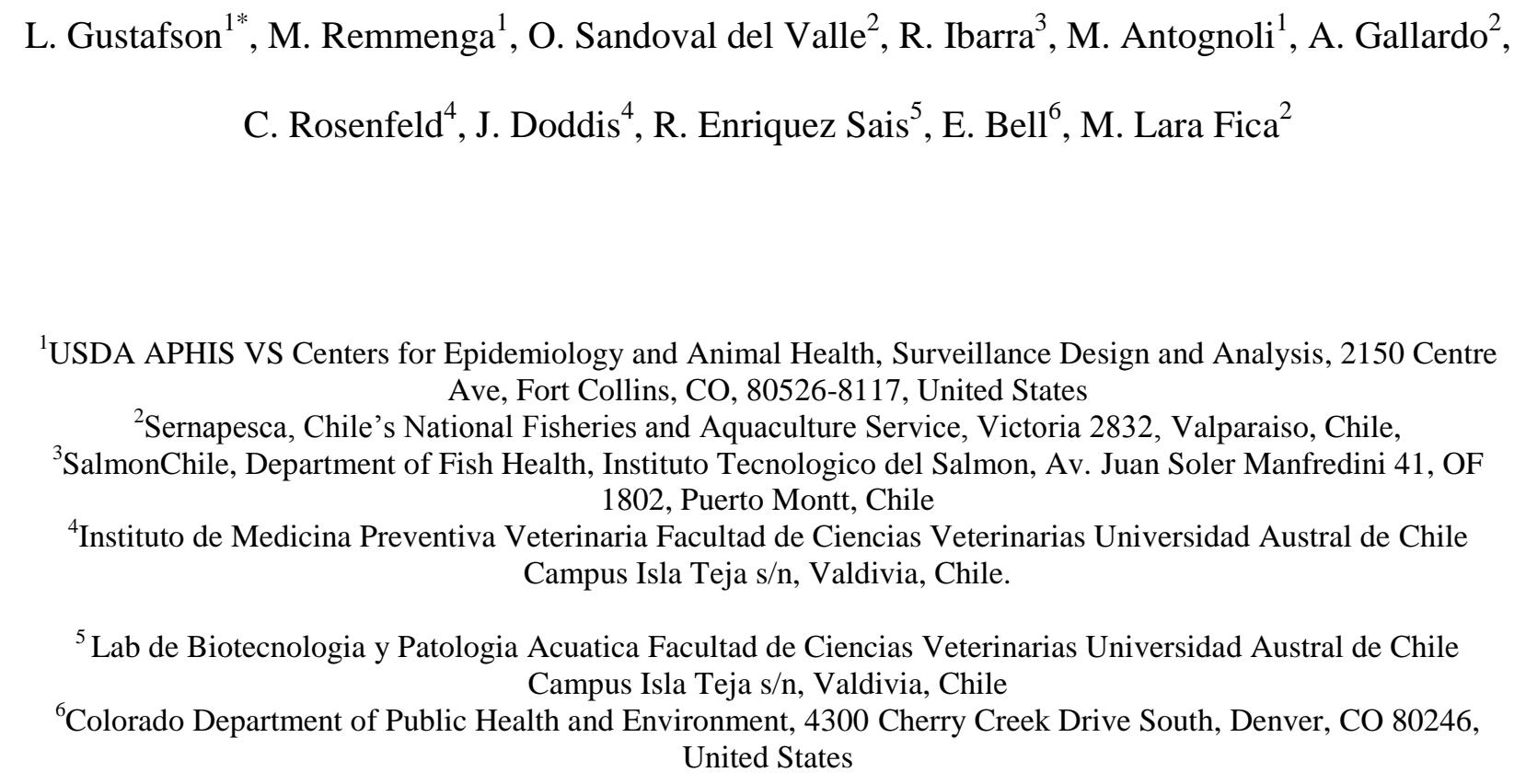

${ }^{*}$ Corresponding author: lori.l.gustafson@ aphis.usda.gov; +1 9704947297 (phone); +1 9704947174 (fax) 
Area management, the coordination of production and biosecurity practices across neighboring farms, is an important disease control strategy in aquaculture. Area management in aquaculture escalated in prominence in response to outbreaks of infectious salmon anemia (ISA)

27 internationally. Successes in disease control have been attributed to the separation achieved through area-level synchronized stocking, fallowing, movement restrictions, and fomite or pest control. Area management, however, is costly; often demanding extra biosecurity, lengthy or inconveniently timed fallows, and localization of equipment, personnel, and services. Yet, this higher-order organizational structure has received limited epidemiologic attention.

Chile's National Fisheries and Aquaculture Service instigated area management practices in response to the 2007 emergence of ISA virus (ISAV). Longitudinal data simultaneously collected allowed retrospective evaluation of the impact of component tenets on virus control.

35 Spatiotemporal analyses identified hydrographic linkages, shared ports, and fish transfers from areas with recent occurrence of ISAV as the strongest predictors of virus spread between areas,

37 though specifics varied by ISAV type (here categorized as HPR0 for the non-virulent genotypes, and HPRv otherwise). Hydrographic linkages were most predictive in the period before implementation of enhanced biosecurity and fallowing regulations, suggesting that viral load can

40 impact spread dynamics. HPR0 arose late in the study period, so few HPRv events were

41 available by which to explore the hypothesis of HPR0 as progenitor of outbreaks. However,

42 spatiotemporal patterns in HPRv occurrence were predictive of subsequent patterns in HPR0 43 detection, suggesting a parallel, or dependent, means of spread. Better data precision, breadth 44 and consistency, common challenges for retrospective studies, could improve model fit; and, for 45 HPR0, specification of diagnostic test accuracy would improve interpretation. 


\section{$47 \quad$ Key words}

48 Infectious salmon anaemia, spatiotemporal analysis, bay management, epidemiology, fish health

\section{Introduction}

The emergence of infectious salmon anemia virus (ISAV), first in Norway in 1984 (Thorud

52 and Djupvik, 1988), then North America, Scotland, Faroe Islands, and most recently Chile

53 (Godoy et al., 2008), precipitated a new era in marine salmon farming. ISA disease typically

54 presents as septicemia with various combinations of lethargy, anemia, exophthalmia, ascites and

55 hemorrhagic lesions in affected fish. ISAV's potential to cause severe mortality and impacts to

56 trade, and, ironically, its responsiveness to mitigations following early detection, advanced a

57 shift from site to regional organization of farming activities. Termed neighborhoods, bay

58 management areas, regions, or zones, we hereafter refer to geographic clusters of marine farms

59 as areas, and strategies for their coordination as area management.

60

Through area management, farms in common waters operate with shared principles and

61 constraints and shared attention to preserving fish health and environmental quality in their

62 region. While much of this coordination is industry-led, responsible use of any common

63 resource is best managed under regulations that ensure consistent and fair practice. Thus,

64 governments may set and enforce standards for disease prevention, reporting, and response;

65 fostering natural 'breaks' in host exposure to pathogens through uniform fish density limits, 66 stocking dates, fallowing periods, traffic patterns, biosecurity, or integrated pest management 
67 routines, for example. On the whole, regional coordination of disease response has been

68 successful, and credited with the reduction or resolution of ISA disease within years of its

69 emergence (Ellis et al., 2006; Murray et al., 2010; Christiansen et al., 2011; Alvia et al., 2012).

70 As such, area management appears a mainstay of marine salmonid farming in many locations

71 (Chang et al., 2007; CoGP Management Group, 2010; USDA APHIS et al., 2010; Rimstad,

72 2011; Kristoffersen et al., 2013).

ISAV control, however, is complicated by the need for continued vigilance given concern

74 about whether non-clinical variants (HPR0) could be progenitors or harbingers of future

75 outbreaks, versus sequelae or corollaries to outbreak strains (Kibenge et al., 2007; EFSA, 2012;

76 Kibenge et al., 2012). Termed HPR0, referring to a non-deleted highly polymorphic region

77 (HPR) of segment 6 of the ISAV genome, these non-clinical variants (also typically

78 characterized by an insertion in segment 5) are not implicated in ISA pathology and not

79 cultivable on cell culture (Kibenge et al., 2009; Godoy et al., 2013), but are considered possible

80 evolutionary progenitors of ISAV outbreak variants (HPRv). Often first observed during

81 resolution of an outbreak, HPR0 typically persists, and at times is quite prevalent (Kibenge et al.,

82 2009; Christiansen et al, 2011; Lyngstad et al., 2011; Vanderstichel et al., 2015), even after

83 apparent extirpation of HPRv. Consequently, though area management is generally successful in

84 the control of ISA, complete eradication of ISAV including HPR0 has proven difficult. Further,

85 re-emergence of ISA, though at a much reduced level, sometimes follows resolution of an initial

86 epidemic (Godoy et al., 2013). Whether explained by genetic shifts from non-virulent (HPR0)

87 variants, unidentified reservoirs, un-mitigated pathways of introduction, or some combination,

88 remains undetermined and signifies the need for research at broader scales. 
This tenuous success of area management is also hard-earned. Single year-class farming,

90 synchronized fallows, and restrictions on activities involving multiple bays are costly and

91 laborious. Sound practices demand dedicated personnel, equipment and vessels, shared

92 information, and creative solutions to ensure continuous market availability of an otherwise

93 punctuated supply of product. And, improperly defined or enforced management areas incur

94 theses costs without benefits of real protection. Consequently, studies to discern the relevance

95 and proper functioning of components of area management are crucial. A number of novel

96 epidemiologic studies examine disease risk on and between farms (Scheel et al., 2007; Lyngstad

97 et al., 2011; Mardones et al., 2014; Rees et al., 2014; Rosenfeld et al., 2015). Yet, field data to

98 explore the efficacy of mitigations on pathogen spread between areas are limited in scope or

99 baseline, often obstructed by missing data for key variables (e.g., records of transits between

100 areas), lack of statistical 'controls' (e.g., areas absent a particular mitigation), or time required

101 for retrospective analyses. Expert elicitations (Gustafson et al., 2014) or simulations (Salama

102 and Rabe, 2013) have been used for decision support. However, evaluation of field data, when

103 those data become available, remains an important standard.

104 Empirical data collected by Chile's National Fisheries and Aquaculture Service (Sernapesca),

105 with local knowledge of area connectivity, afforded the unique opportunity to examine ISAV

106 control at an area management scale. The objective of this longitudinal spatiotemporal study

107 was to assess the predictive impact of contact networks on observed patterns of ISAV spread

108 between marine areas in Chile. 


\subsection{Study Region and Period}

The emergence of ISAV (Genotype I) in Chile was confirmed and declared by Sernapesca in July 2007 based on results of investigations initiated June 2007 (Godoy et al., 2008). This study covered all areas farming Atlantic salmon (Salmo salar) between June 2007 and December 2012 in Chile's marine Regions de los Lagos and Aysén (Figures 1 and 2;

\section{http://www.sernapesca.cl/index.php?option=com_content\&task=view\&id=128\&Itemid=293).}

This period covers the emergence of ISAV in Chile (Godoy et al., 2008), as well as a period of temporary resolution of ISA disease dominated instead by detections of a non-virulent ISAV variant termed HPR0 (Godoy et al., 2013). Sanitary regulations for aquaculture in Chile (RESA D.S. No.319-01), updated in March 2009 (e.g., mandating a rolling implementation of enhanced biosecurity and synchronized fallowing), also evolved throughout the study period (Sernapesca, 2001). Thus, early in the study, geography and site-level biosecurity were key facets supporting area separation; later in the study, enhanced biosecurity standards improved their distinction.

$$
\text { We analyzed HPRv data over the full time period. However, the } 2009 \text { revisions likely }
$$
instigated a gradual reduction in circulating levels of virus in the environment, and consequent exposure pressures. Thus, we also analyzed the HPRv dataset piecemeal for the periods preceding- versus starting- April 2009, with the goal to identify whether pathways changed in prominence following enhanced mitigations. In contrast, because the first designation of HPR0 occurred after March 2009, the HPR0 evaluation comprises only a single segment of the study period. In all cases, we analyzed predictors of ISAV HPRV and ISAV HPR0 occurrence separately. Thus, we examined the dataset in 4 ways: (1) HPRv over the full period (months 167), (2) HPRv pre-2009-regulations (months 1-22), (3) HPRv post-2009-regulations (months 23- 
133 67), and (4) HPR0 over a final segment of the study period (months 33-67). March 2009

134 corresponds to month 22 of the study.

135 All active Atlantic salmon (ATS) farming sites in the study regions and period were

136 included, where active was defined as 4 or more months of continuous operation. Marine sites

137 typically hold fish from sea transfer as smolts through to harvest; although some estuary sites

138 rear smolts prior to transfer to higher salinity locations. A typical 'production cycle' for ATS in

139 the seawater stage is 21 months in duration, followed by a 3 month fallow. We considered a

140 cohort of fish to be those of a single site and production cycle. The term 'site' is used to describe

141 an individual marine farm rearing ATS; the term 'area' refers to a collection of neighboring sites

142 distinguished from other areas by location and contact networks. Study area delineations match

143 those currently employed by Sernapesca, described locally as barrios. Lastly, we used the term

144 'ISAV incidence' to describe counts of ATS cohorts (sites/production cycles) newly meeting

145 Sernapesca's ISAV case definitions (ISAV designations) in a given month and area. Site names,

146 ownership and address were withheld or coded by Sernapesca to protect confidentiality.

2.2 ISAV Surveillance and Constraints

149 Routine surveillance for ISAV followed Chile's federal program standards

150 (http://www.sernapesca.cl/index.php?option=com_remository \&Itemid=246\&func=fileinfo\&id=7

151 438). Marine sites were visited monthly, or more frequently, by licensed veterinarians under

152 private or federal (Sernapesca) affiliation. At each visit a minimum of 30 fish were collected,

153 selected from at least 3 cages. Tissue pools from 1-3 fish of kidney, heart, and (starting July

154 2008) gill tissues were submitted to official laboratories in Chile for diagnostic testing using real- 
155 time reverse-transcription-polymerase chain reaction (RT-qPCR) and confirmatory sequencing.

156 All laboratories employed TaqMan probes (Snow et al., 2006) for RT-qPCR starting December

1572008 (a Sybr green probe was used in some laboratories prior). Moribund fish or fresh

158 mortalities were targeted when possible.

159 As noted earlier, this study covers a dynamic period encompassing broad changes in the 160 ISAV landscape, from detection, response, and resolution of the initial ISAV clinical outbreaks

161 to the appearance and apparent ubiquity of an HPR0 variant. Thus, surveillance program

162 standards also evolved, including a 2011 revision of Sernapesca's criteria for the designation of

163 ISAV cases (see below). To address this natural drift in detection capacity, we applied or

164 acknowledge the following rules and constraints. (1) The outcome variables estimate apparent

165 rather than actual ISAV occurrence, as counts were not adjusted for system or diagnostic test

166 sensitivity and specificity. (2) We used Sernapesca's 2011 revised definitions to standardize

167 ISAV designations throughout. (3) Except in the case of cross-variant prediction (specifically,

168 HPRv as a predictor of HPR0), we evaluate only short-term lags ( $\leq 5$ months) and minimize

169 comparisons over broad time intervals. And, (4) we report incidence of new ISAV designations

170 as counts, rather than rates, as the rate denominator (number of susceptible cohorts) was only

171 indirectly tracked during the study period. In summary, this study examines temporal

172 relationships between apparent ISAV incidence in marine areas and their contact networks,

173 where incidence measures counts of cohorts newly meeting Sernapesca 2011 ISAV case

174 definitions (designations) in a given month. 


\subsubsection{Outcome Variables (ISAV Incidence)}

New ISAV designations were tallied by area, month, and type (HPR0 or HPRv). ISAV HPR0 refers to ISAV genotypes considered non-virulent, absent any deletions in the HPR of segment 6. ISAV HPRv refers to any ISAV genotype containing deletions in the HPR of segment 6 . While sequencing more of the genome would help differentiate higher-order degrees of relatedness within or across these groupings (Nylund et al., 2003; Devold et al., 2006; Kibenge et al., 2009; Godoy et al., 2013), full sequencing data were unavailable for most designations. Consequently, phylogenetics were not further explored in this study.

ISAV designations were based on Sernapesca's case definitions for ISAV HPR0 and ISAV HPRv. ISAV designations were applied to sites where two or more fish (collected 48 days or less apart) from any one or more cages with samples screening positive by RT-qPCR also tested positive by sequencing; or (especially prior to 2011 when sequencing was less common) if RTqPCR results were corroborated by mortality, clinical or pathological signs consistent with ISA. Sernapesca ascribed ISAV designations only to initial findings of HPR0 and HPRv in a given site and production cycle. HPRv designations led to depopulation of affected net-pens, and sometimes the entire site. HPR0 designations led to increased frequency of surveillance. Cagelevel (within site) data were not available for analysis. Consequently, outcome variables track initial ISAV findings in a given site and production cycle (cohort). However, a single site might accumulate multiple designations, each for a different cohort, over the course of the study.

ISAV HPRv incidence per area and month was the outcome variable for HPRv analyses; ISAV HPR0 incidence per area and month was the outcome variable for HPR0 analyses. ISAV incidence here describes the count of ISAV case designations newly ascribed in any given area 
and month. As Sernapesca only ascribed designations to the first occurrence per cohort, this

200 count is measured in cohorts. Harvest, stocking and depopulation dates by which to differentiate

201 production cycles for non-affected sites were unavailable for design of a comparable rate

202 denominator. Thus, our ISAV incidence variables capture the count (not rate) of new (rather

203 than existing) ISAV occurrences in each time-space block. To address this deficit, we scripted a

204 control variable (susceptible sites, see below) as a general proxy for area ISAV susceptibility. A

205 control variable was included in all multiple regression models. stocking and harvest dates were not available, Sernapesca did track ATS biomass, abundance, 210 sea lice and transfer data through mandated monthly industry reports. ATS biomass here refers 211 to units of million $\mathrm{kg}$ fish per 5,000 hectares ( $\mathrm{kg} / \mathrm{hectare})$, and ATS abundance here refers to 212 units of 100,000 fish per 5,000 hectare (fish/hectare), where five thousand hectares approximates 213 the size of the smallest management area in Chile. However, reliability of biomass, abundance 214 and sea lice reporting varied throughout the study period. Consequently, we created a simplified 215 summary variable, 'susceptible sites', which tallied, by area, the number of ATS sites active 216 (non-zero biomass) in a given month. Biomass records suggesting abbreviated occupancy $(<4$ 217 months in a row) were questioned and (1) discussed individually with Sernapesca staff, and (2) 218 zeroed if confirmation of occupancy through other records was not possible. Overlap in several 219 datasets provided the opportunity to check and resolve discrepancies. For example, if a site's 220 reported biomass was zero in a given month, but fish transfer records or sea lice data confirmed 
221 site activity, and Sernapesca staff agreed, we labeled biomass 'missing' (rather than zero) and

222 classified the site 'susceptible' for that period. Alternative species (e.g., Oncorhynchus mykiss,

223 O. kisutch, or $O$. tshawytscha) were not included in these calculations.

\subsubsection{Contact Networks between Areas}

The predictive impact of ISAV incidence in marine contact networks on ISAV incidence in

227 each area was analyzed through time. Contact networks for a given area were defined as

228 constellations of areas with shared access to its ports, processing plants, or acopios (holding

229 areas for live fish prior to processing), shared hydrographics, or sources for fish transfers. These

230 five contact networks form the basis of our evaluation.

$231 \quad$ Hydrographic networks were estimated by Sernapesca and Intesal representatives in

232 discussion with local subject matter experts. Water circulation is modeled for only limited

233 portions of Chile's coastline (Olivares et al., 2015). Connectivity was thus based on working

234 knowledge of prevailing hydrographic patterns. Experts were asked to judge relative extent of

235 connectivity between areas within a typical diurnal period. Specifically, they were asked to list,

236 for each area, those areas they considered to be within 1 day reach in time, and 'upstream' per

237 direction of prevailing currents. The same experts scored connectivity for all areas. Thus,

238 decisions about how to gauge distance, time, or seasonal flux were applied with consistency.

239 Areas known or permitted by Sernapesca to use ports, processing plants, or acopios in a 240 given ('destination') area were denoted its 'suppliers'. Contact networks reflect allowed (rather 241 than actual) usage patterns for ports, processing plants or acopios. Defined networks remained 242 consistent throughout the study period, and thus did not capture volume or seasonality of use. In 
243 contrast, dates and direction of transits moving fish between areas for further grow-out were

244 individually tracked in industry reports to Sernapesca (RESA D.S. No. 319-01); thus, 'fish

245 transfers' captures both frequency and seasonality of fish shipments. Transfer variables include

246 movements of all farmed salmon or trout species (ATS, Oncorhynchus mykiss, O. kisutch, or O.

247 tshawytscha), providing both origin and destination were marine study areas.

248 Though most network memberships were constant, their ISAV incidence was time-variant

249 (evaluated monthly). Predictive variables were created for each destination area by summing

250 ISAV incidence across its network suppliers, each month. For example, for a given destination

251 area, the predictive variable 'processing plant suppliers' is the monthly sum of ISAV incidence

252 across all areas authorized to use its processing plants. Similarly, 'acopio suppliers' sums ISAV

253 incidence across areas authorized to use its acopios, 'port users' across areas authorized to use its

254 ports, 'neighbor' across areas considered 'upstream' hydrographically of the destination area,

255 and 'fish suppliers' across (marine) areas sourcing its fish for stocking or further grow-out.

256 Transfers or contacts within area (self-transfers) were excluded from these counts.

$258 \quad 2.4$ Data Analysis

259 Data were cross-sectional and time-variant, covering 56 cross-sections, i.e., areas (21 in 260 Region de los Lagos; 35 in Region Aysén), and 67 time intervals, i.e., months. Using SAS

261 (version 9.4) statistical software, we ran time-series cross-sectional (TSCS) regression analyses 262 to identify predictors of ISAV HPR0 and ISAV HPRv incidence over these 56x67 area-month 263 observations. We explored univariate relationships between area-month HPRv incidence with 264 the sum of HPRv incidence in 'neighbor', 'acopio supplier', 'plant supplier', 'fish transfer 
265 supplier', and 'port user' areas the same month as well as 1-5 months prior (lags). We also

266 explored univariate HPRv relationships with area incidence of HPR0 up to 5 months prior.

267 Number of susceptible sites, sea lice counts, and two measures of density ( $\mathrm{kg} / \mathrm{hectare}$ and

268 fish/hectare) were similarly evaluated. However, sea lice counts were excluded from multiple

269 regression as these data were only sporadically reported during the study period. To prepare for

270 multiple regression, we explored whether region was a significant predictor $(\alpha=0.05)$ of the

271 outcome variable, in which case further analyses were conducted separately for Region de los

272 Lagos and Region Aysén to best discern regional differences. We repeated analyses with area-

273 month HPR0 incidence as the outcome variable. For HPR0 analyses, however, we carried lags

274 of HPRv incidence out to 37 months. This extended lag period was made possible by the

275 delayed initial appearance of HPR0 in the study region.

276 Multiple regression models were fit to the TSCS data, modeling HPRv and HPR0 separately.

277 As variable lags were tightly correlated, we identified the most significant lag (evaluated out 5

278 months for most variables), or 3-month rolling sum or average of lags, for each predictive

279 variable. We used stepwise forward selection to identify the most parsimonious model, entering

280 the single most important lag for the next selected variable (based on R-square values, given p-

281 values $\leq 0.05$ ) at each intermediary step. Model fit was judged, and best models chosen, from

282 adjusted R-square statistics. The most important lag of the outcome variable (representing an

283 area's prior ISAV incidence) was included in the predictive model to address autocorrelation.

284 We excluded interaction terms; though many were statistically significant, they added only

285 incremental strength and little interpretive value to the models. We used Fuller and Battese

286 specifications assuming random time and space components in all TSCS regression models. 
To discern connectivity 'hot-spots', we identified areas whose outbreaks were repeatedly

288

associated through time with outbreaks in 'upstream' or 'supplier' areas. This was done by running the multiple regression models on each area separately and noting which, if any, predictive factors were statistically significant through time $(\alpha=0.05)$. Individual area analyses included 35 and 67 time periods for HPR0 and HPRv, respectively. Results are reported as the proportion of areas showing a statistically significant association for a given factor.

\section{Results}

\subsection{Data Summary}

Fifty-six areas actively farmed ATS in one or more sites during some or all of the 67-month study period. The number of susceptible ATS sites per area varied over the study period (Figure 3). During the full study period, $96 \%$ of study areas detected ISAV HPRv or ISAV HPR0 at some point in time. A total of $227 \mathrm{HPRv}$ and $125 \mathrm{HPR} 0$ site designations were accumulated during the study period. HPRv occurred at some point in $95 \%$ of areas in Region de los Lagos and $80 \%$ in Region Aysén; and HPR0 occurred in $81 \%$ of areas in Region De Los Lagos and 80\% in Region Aysén. HPRv incidence was concentrated during months 2 to 39 of the study period (99\%), with the remainder occurring in months 53-54 (Figure 4). HPR0 ISAV was detected only during the latter portion of the study, from months 33 to 65 (Figure 5). We were able to carry lags for all predictive variables, except sea lice, 1-5 months back (t-5) for any point in the study. Sea lice data were available for month 9 of the study onward, thus lagged (t-5) sea lice data were only available starting month 14 . 
3.2 Univariate Analyses and Modeling Decisions

Univariate analyses on ISAV HPRv and ISAV HPR0 incidence (separately) identified

312 significant associations with the ISAV status of 'neighbor' areas, or areas sourcing processing

313 plant ('plant') users, 'acopio users', live fish transfers ('fish suppliers'), and 'port users' in the 314 same month and/or 1-5 months previous (termed lags, Tables 1-2). ISAV incidence was also 315 associated with number of susceptible sites for both ISAV types.

316 Correlation analyses found tight relationships between processing plant and acopio predictive 317 variables, and moderate relationships between those and port variables (Table 3). Comparative 318 univariate TSCS regressions on base variables (i.e., without lags) gave processing plant the 319 smallest $\mathrm{R}^{2}$ of the three for both $\operatorname{HPRv}(0.0459,0.0262$, and 0.0236 for port, acopio and plant 320 respectively) and HPR0 (0.0096, 0.0037, and 0.0039 for port, acopio and plant respectively) 321 prediction. We thus eliminated processing plant variables from further modeling.

322 Neither current nor previous HPR0 status was predictive of HPRv incidence for the short lag 323 periods (1-5 months) examined. However, because HPR0 occurred for the first time much later 324 in the study period, we were able to examine its relationship with the occurrence of HPRv up to 32537 months (lags) prior. In this case, univariate analyses for ISAV HPR0 prediction revealed 326 statistically significant relationships with HPRv occurrence months 30-33 prior.

327 Region was found to be statistically significant in HPRv analysis (except the post-2009328 regulation period), but insignificant for HPR0. Consequently, multiple regression models were 329 built for Region de los Lagos and Region Aysén separately for HPRv (except the post-2009330 regulation period), but combined for HPR0 analysis. 


\subsection{HPRv Multiple Regression Analyses}

The multiple regression model that best fit HPRv incidence in Region de los Lagos by area334 month included: (1) the area's prior HPRv incidence (summed over the preceding three months),

335 (2) the number of susceptible sites in the area (three months prior), (3) the sum of HPRv

336 incidence (two months prior) in areas using its ports, (4) the sum of HPRv incidence (one month 337 prior) in areas sourcing any fish transfers for continued grow-out, and (5) the sum of HPRv 338 incidence (one month prior) in neighbor areas considered 'upstream' hydrologically (Table 4).

339 The best fit multiple regression model describing HPRv incidence in Region Aysén by area340 month named similar predictors (different lags) with the exception of the port variable (Table 4).

341 April 2009 marked the beginning of a transition to synchronized fallowing, enhanced 342 processing plant biosecurity, and restricted acopio use during outbreaks. Separate analyses on 343 periods pre- and post-transition suggest that site volume and hydrographics dominate as 344 predictors of spread in the initial stage of the study (Table 5), while movement patterns, e.g., via 345 fish transfers and port usage, predominate later in the study (Table 6). Acopio and HPR0 346 predictors exert negative, but significant, effects in the later stages of the outbreak.

\subsection{HPR0 Multiple Regression Analyses}

The best multiple regression model for HPR0 incidence in the combined regions by areamonth included: (1) the area's prior HPR0 incidence (1 month prior), (2) the average number of 351 susceptible sites in the area (over the current and prior three months), (3) the total ATS fish per 
352 hectare in the area (two months prior), (4) the sum of HPR0 incidence (the same month) across

353 areas using its ports, (5) the sum of HPR0 incidence (1 month prior) across areas considered

354 'upstream' hydrologically, and also (5) HPRv incidence in the area (31 months prior) (Table 7).

\subsection{Regression Model Explanatory Power}

Though predictive variables were highly significant (low p values), the models explained

358 only a portion of spatiotemporal spread (adjusted R-square range 8-30\%). Described models

359 explained the most variability in HPRv in Region de los Lagos, less for HPRv in Region Aysén

360 or HPR0 in the combined regions, and extremely little for HPRv post-2009-regulations.

\section{7 'Hot Spot' Analyses}

Follow-up analyses on individual areas identified those responsible for a substantial portion

364 of predictive strength in TSCS regressions. Table 8 displays the proportion of areas with

365 repeated associations between ISAV status and area connectivity measures over time $(\mathrm{p}<0.05$,

366 full study period). Additional areas may also contribute to the predictive strengths of TSCS

367 regression models; this table simply highlights those with sufficient repetition of associated

368 events over time to independently demonstrate significance. Numerators represent the count of 369 areas showing a statistically significant pattern of association, over time, between the predictor 370 and ISAV incidence. Denominators represent the total number of areas exhibiting that predictive 371 factor. For example, if 7 areas made their ports available for use by vessels originating in other 
372 areas (and experienced HPRv during the study), and HPRv incidence in originating areas

373 recurrently preceded HPRv events in 2 of those 7 , the reported proportion is 2/7.

\section{Discussion}

Area management is often coined to improve disease prevention and response in aquaculture

378 and reduce disease impacts to fish, industries and environment. However, constraining - as it 379 does - product supply and work force continuity, and demanding replication of many services, 380 area management is also difficult to orchestrate and costly to maintain. Epidemiologic studies of 381 disease spread identify strengths and weaknesses in disease control programs (Peeler and Taylor, 382 2011). In the aquatic environment, pathogen transmission is often attributed to large-scale 383 processes such as water currents (Gustafson et al., 2007; Murray et al., 2010), vessel transit 384 (Murray et al., 2002; Mardones et al., 2009) or wild fish movements (Arechavala-Lopez et al., 385 2013). Traditionally, however, field studies evaluate site-to-site rather than area-to-area disease 386 spread dynamics, which can make it difficult to characterize higher order patterns or controls.

387 Our spatiotemporal study of ISAV spread throughout Chile's Regions de los Lagos and 388 Aysén was geared to specifically examine the efficacy of area-level controls in aquaculture. 389 Several factors predicted monthly area incidence of ISAV HPRv in the current study. These 390 included (1) the area's prior HPRv incidence, (2) the number of susceptible sites in the area, (3) 391 HPRv incidence in neighbor (hydrographically 'upstream') areas, (4) HPRv incidence in areas 392 sourcing transfers of live fish for further grow-out, or (5) for Region de los Lagos, HPRv 393 incidence in areas known to utilize its ports. The most predictive lag for each variable differed, 
394 but typically ranged 1-3 months prior. Results direct local attention to extant exposure pathways 395 and geographic areas that might benefit from revised boundaries, mitigations, or additional 396 research, and inform area management design for other countries or diseases.

The relative shortage of area management evaluations preceding this study may result from 398 data structure and retrieval issues. Applied uniformly, area mitigations often leave few to none 399 for statistical controls. Further, large datasets, especially those collected routinely and evaluated 400 in retrospect, may be lacking in quality, as reliance on multiple producer reports, turnover of 401 personnel responsible for the data, limited scope, or few opportunities (during emergency 402 response) for field validation and quality control, are typical complications.

Data quality varied in our study as well. The outcome variable ISAV HPRv incidence, based 404 on routine veterinary site visits and mandated testing at all sites, is likely highly dependable. In 405 comparison, the contact networks generating many of the predictive variables (also counts of 406 ISAV incidence) were coarse, were based on expected rather than observed patterns of use. 407 However, scripted through consensus by local experts, these are likely well-informed. In 408 contrast, the control variable for area susceptibility was inferred through a combination of 409 measures, each complicated by missing data. Redundancies across datasets allowed us to form a 410 proxy variable (susceptible sites) inferring site activity from either non-zero biomass reports or 411 documented production activities (e.g., sea lice surveys or fish transfers). Related reporting 412 errors should occur most often in ISAV negative sites under the least scrutiny. However, 413 described imprecisions in variable classification reduce model clarity and sensitivity to existing 414 trends. This study suggests future benefit from refined tracking of aquaculture production 415 activities, e.g., stocking and harvest dates, freshwater contacts, and traffic flow between areas; 
416 purposive inclusion of redundancies across some variables; and periodic field validation of

417 random entries to strengthen data quality.

418 Our study spans the pre- and post- adoption of March 2009 federal regulations mandating

419 enhanced biosecurity. Enhancements included, among others, all-in all-out farming,

420 synchronized fallows, restrictions on fish movements and egg imports, reductions on total

421 biomass; and also standards for the treatment of wastes and effluents from processing plants,

422 mortality collections and harvest operations (Alvial et al., 2012). Early voluntary adoption of

423 best practices by the industry staged the groundwork for these regulations (Alvial et al., 2012);

424 and mandates were implemented in stages, with uniform adoption achieved by October 2012.

425 Thus, prior to April 2009, areas relied predominantly on geography and site-level biosecurity to

426 maintain epidemiologic separation from other areas; and, starting April 2009, enhanced

427 biosecurity standards applied at the area level gradually strengthened their separation.

428 Hydrographic patterns were most predictive in the early period of study. Waterborne spread

429 of pathogens between marine sites or areas has been implicated in other parts of the world

430 (Scheel, I. et al., 2007; Gustafson et al., 2007). And space-time cluster analyses support a

431 hydrographic influence, also, on site-level transmission of ISAV in Chile (Mardones et al., 2009;

432 Godoy et al., 2013; Vanderstichel et al., 2015). Vast distances separate many Atlantic salmon

433 production areas along Chile's extensive coastline (Figures 1, 2), however hydrographic

434 connectivity also predicted spread between areas in the current study. Hydrographic dispersion

435 models are only available for select regions in Chile (Olivares et al., 2015). Our study

436 complements these modeling efforts by identifying areas with apparent consequential

437 connectivity (per disease events repeatedly linked in time) to their neighbors. Results prioritize 
438 locations for future research, e.g., hydrographic modeling or field investigation of alternate 439 explanations for the observed spatial connectivity (e.g., wild fish, sea lice, birds, other fomites).

440

441

442

443

444

445

446

447

448

449

450

451

452

The influence of hydrographics diminished following 2009 regulations. A sustained reduction in HPRv incidence tracked a sharp decline in susceptible sites (Figures 3, 4), giving credence to the benefits of area management. Reduced biomass and optimized biosecurity should lessen virus loads in the environment, and could explain the reduction in relevance of transmission pathways, including the reach of waterborne spread. These observations also support macrozone concepts that adjust the size of management areas according to pathogen environmental persistence (Rimstad and Mjaaland, 2002) and stage of outbreak.

Fish transfers were more common in advance of 2009 regulations. Later movements were scarce, e.g., non-ATS species, or smolts transferred from estuarine holdings. However, fish transfer variables remained statistically significant in the later period, suggesting the few transfers that did occur were predictive of subsequent outbreaks. Earlier studies associate site risk of disease with intensity of incoming fish shipments (Murray et al., 2002; Mardones et al., 2014). Our data suggest that fish transfers also impose risks to the encompassing area.

Port risks were most significant in the Region de los Lagos region, and later period, of study. Commercial ports are few in Chile; thus, port-equipped areas share their land access with vessels originating from outer locations, neighboring or distant. While standard practices separate harvest vessel from routine port landings in time or space, the current study suggests other risks remain. Related variables (processing plant and acopio suppliers) were significant in univariate analyses, but did not improve multiple regression fit or prediction. Lack of independence may explain the parsimony. Acopios, temporary holdings for fish pre-processing, and processing 
460 plants are often located in vicinity of ports. Ports, however, experience added risks of smolt and 461 feed delivery, vessel cleaning, fisheries and other business ventures. And, while regulations 462 improved biosecurity of harvest and processing operations, and constrained acopio access to 463 farms from areas deemed ISAV-free, port biosecurity was not similarly addressed.

HPR0 was not generally predictive of HPRv incidence in our study. As $97 \%$ of the HPRv events occurred prior to initial detection of HPR0, statistical relevance was not expected.

466 However, in the single model (Table 6) in which HPR0 was a predictor of HPRv status, the two 467 variables were negatively associated. In other words, where HPR0 shows any predictive effect at 468 all for HPRv, it is a slightly protective one. This contrasts with earlier reports of HPR0 469 detections preceding the emergence of phylogenetically-related HPRv, as in two 2013 cases of 470 ISA in Chile (Godoy et al., 2013), retrospective field study in Norway (Lyngstad et al., 2011), 471 and the documentation of co-occurring HPR0 and HPRv variants of similar genetics in 472 individual fish (Cardenas et al., 2014). However, our findings offer context suggesting that 473 HPRv emergence from HPR0 is likely a low probability event. Model fit, and predictive 474 variable strength, were much reduced post-2009 biosecurity regulations. Consequently, cautious 475 interpretation suggests the need for further field study of the epidemiologic relationship between 476 HPRv and HPR0 variants, and management factors that may influence their co-evolution.

477 ISAV establishment may have been density-dependent in the studied outbreak. The control 478 variable 'susceptible sites' bounds maximum ISAV incidence. However, whether it also reflects 479 volume of farming activities that could introduce pathogens (Arechavala-Lopez et al., 2013) or 480 some undefined carrying capacity which (when exceeded) could raise disease susceptibility, is 481 unknown. Specific, but less reliable, biomass variables dropped out of most models. At the time 482 of study, federal regulations limited fish numbers per cage, but not cage numbers per site. 
483 Models addressing carrying capacity or optimum stocking densities to advise aquaculture siting 484 may ultimately benefit disease control (Salama and Rabe, 2014).

Analyses for HPR0 were least conclusive. Similar patterns between HPRv and HPR0 occurrence suggest parallel mechanisms of spread. In fact, a predictor for HPR0 occurrence was

487 HPRv occurrence in the same area, years prior. However, HPR0 models were of limited 488 strength; perhaps because this variant was captured with less accuracy. The sensitivity of RT489 PCR for HPR0 is to date undescribed. HPR0 is non-cultivable; and confirmatory tests 490 (sequencing) utilize screening test products and thus do not meet the independence assumption 491 required for latent-class sensitivity estimation (Pouillot et al., 2002). Further, studies show 492 HPR0 tissue tropism preference for gill over kidney (Christiansen et al., 2011); and gill was not 493 sampled in the initial period of study. Consequently, it is difficult to decipher whether absence 494 of detections truly signifies HPR0 absence; and, whether a positive finding indicates new 495 introduction or simply chronic low-level infection (Kibenge et al., 2008; Godoy et al., 2013).

496 These uncertainties will restrict interpretation of HPR0 field studies until more is known about 497 the importance and persistence of the virus in both host and environment. Imprecise variable classification, as noted earlier, limits the predictive strength of all models 499 in this study. However, low $\mathrm{R}^{2}$ values suggest key predictors may also be missing from the 500 analyses. Undescribed variables here include, among others: the health and distribution of feral 501 salmonids in the study region (Rosenfeld et al., 2009; Gonzalez et al., 2011; Miranda et al., 2012; 502 Olmos and Schulze, 2013); the distribution of secondary processing plants (e.g., for value-added 503 processing of salmonids, primary processing of molluscs, or other fisheries harvests); patterns of 504 sea lice infestation (Valdes-Donoso et al., 2013; Kristoffersen et al., 2013; Godoy et al., 2013); 505 the impact of management practices or other co-infections on ISAV susceptibility (Godoy et al., 
2013; Rees et al., 2014); and the impact of invertebrate fauna, benthic or environmental

507 conditions on virus persistence (Gonzalez et al., 2011). Additionally, exposure via land-based or

508 freshwater activities, e.g., broodstock lineage (Vike et al., 2009; Marshall et al., 2014), secondary

509 service providers, hatcheries or other holdings, deserves further study (Gustafson et al., 2014).

510 The natural refinement of surveillance and response strategies seen through time and

511 experience with emerging pathogens also confound retrospective analyses. We expect that initial

512 ISAV events were slower to detect and confirm than those occurring later. Similarly, we expect

513 that viral loads were better contained following implementation of 2009 revisions to sanitary

514 regulations; and resulting relevance of transmission pathways would vary through time.

515 However, such business process improvements should reduce, rather than exaggerate, measured

516 associations. Thus, we expect our findings are conservative. Periodic evaluations of field data

517 shed light on epidemiologic drivers of disease emergence and resolution. They also provide

518 opportunities to improve data repositories, variables tracked, and their verification procedures.

\section{Acknowledgements}

This work was supported by the U.S. Department of State through interagency agreement

522 with USDA APHIS VS CEAH under the U.S.-Chile Environmental Cooperation Agreement.

523 Extensive in-kind support was also provided by Chile's Sernapesca, SalmonChile-Intesal, and

524 Universidad Austral de Chile. We also thank the many industry stakeholders, university and

525 government representatives in Chile that facilitated site visits, shared information and promoted

526 discussions that provided important direction for this study. 


\section{References}

Alvial, A., Kibenge, F., Forster, J., Burgos, J.M., Ibarra, R., St-Hilaire, S. 2012. The recovery of the Chilean salmon industry: The ISA crisis and its consequences and lessons. The Global Aquaculture Alliance. 83 pp. http://www.gaalliance.org/cmsAdmin/uploads/GAA_ISA-Report.pdf

Arechavala-Lopez, P., Sanchez-Jerez, P., Bayle-Sempere, J.T., Uglem, I., Mladineo, I. 2013. Reared fish, farmed escapees and wild fish stocks - a triangle of pathogen transmission of concern to Mediterranean aquaculture management. Aquaculture Environment Interactions 3, 153-161.

Cardenas C, Carmona M, Gallardo A, Labra A, Marshall SH: Coexistence in field samples of two variants of the infectious salmon anemia virus: a putative shift to pathogenicity. Plos One 2014, 9:e87832.12.

Chang, B.D., Page, F.H., Losier, R.J., Lawton, P., Singh, R. and Greenberg, D.A. 2007. Evaluation of bay management area scenarios for the southwestern New Brunswick salmon aquaculture industry: Aquaculture Collaborative Research and Development Program final project report. Can. Tech. Rep. Fish. Aquat. Sci. 2722: v+69p.

Christiansen, D.H., Ostergaard, P.S., Snow, M., Dale, O.B., Falk, K. 2011. A low-pathogenic variant of infectious salmon anemia virus (ISAV1 - HPR0) is highly prevalent and causes a non-clinical transient infection in farmed Atlantic salmon (Salmo salar L.) in the Faroe Islands. J. Gen. Virol., 92, 909-918. 
CoGP (Code of Good Practice) Management Group. 2010. A code of good practice for Scottish finfish aquaculture. http://bit.ly/z5LzYv. Accessed 10 Feb 2015.

Devold, M., Karlsen, M., Nylund, A. 2006. Molecular sequence analysis of the fusion protein from infectious salmon anaemia virus (ISAV) isolates: evidence of recombination and reassortment. J Gen Virol 87, 2031-2040.

EFSA Panel on Animal Health and Welfare (AHAW): Scientific Opinion on infectious salmon anaemia (ISA). EFSA Journal 2012, 10:2971-2992.

Ellis, S., L. Gustafson, C. Giray, T. Robinson, F. Marenghi, P. Merrill. 2006. Hydrographics and the epidemiology of ISA: Findings from a high-risk region in Maine and New Brunswick. Bulletin of the Aquaculture Association of Canada. 106(1): 44-51.

Godoy, M.G., Aedo, A., Kibenge, M.J., Groman, D.B., Yason, C.V., Grothusen, H., Lisperguer, A., Calbucura, M., Avendano, F., Imilan, M., Jarpa, M., Kibenge, F.S. 2008. First detection, isolation and molecular characteriziation of infectious salmon anaemia virus associated with clinical disease in farmed Atlantic salmon (Salmo salar) in Chile. BMC Vet Res 4, 28.

Godoy, M.G., Kibenge, M.J.T., Suarez, R., Lazo, E., Heisinger, A., Aguinaga, J., Bravo, D., Mendoza, J., Llegues, K.O., Avendano-Herrera, R., Vera, C., Mardones, F., Kibenge, F.S.B. 2013. Infectious salmon anaemia virus (ISAV) in Chilean Atlantic salmon (Salmo salar) aquaculture: emergence of low pathogenic ISAV-HPR0 and re-emergence of virulent ISAV-HPRA: HPR3 and HPR14. Virology Journal 10, 344-361. 
Gonzales, R.R., Ruiz, P., Llanos-Rivera, A., Cruzat, F., Silva, J., Astuya, A., Grandon, M., Jara, D., Aaburto, C. 2011. ISA virus outside the cage: ichthyofauna and other possible reservoirs to be considered for marine biosafety management in the far-southern ecosysmtes of Chile. Aquaculture 318, 37-42.

Gustafson, L.L., Ellis, S.K., Beattie, M.J., Chang, B.D., Dickey, D.A., Robinson, T.L., Marenghi, F.P., Moffett, P.J., Page, F.H. 2007. Hydrographics and the timing of infectious salmon anemia outbreaks among Atlantic salmon (Salmo salar L.) farms in the Quoddy region of Maine, USA and New Brunswick, Canada. Preventive Veterinary Medicine 78, 35-56.

Gustafson, L., Antognoli, M., Lara Fica, M., Ibarra, R., Mancilla, J., Sandoval del Valle, O., Enriquez Sais, R., Perez, A., Aguilar, D., Madrid, E., Bustos, P., Clement, A., godoy, M.G., Johnson, C., Remmenga, M. 2014. Risk factors perceived predictive of ISA spread in Chile: Applications to decision support. Preventive Veterinary Medicine 117, 276285.

Kibenge, F.S.B., Godoy, M.G., Wang, Y., Kibenge, M.J.T., Cherardelli, V., Mansilla, S., Lisperger, A., Jarpa, M., Larroquete, G., Avendano, F., Lara, M., Gallardo, A. 2009. Infectious salmon anaemia virus (ISAV) isolated form the ISA disease outbreaks in Chile diverged from ISAV isolates from Norway around 1996 and was disseminated around 2005, based on surface glycoprotein gene sequences. Virology Journal 6, 88-104.

Kibenge, F.S.B., Godoy, M.G., Fast, M., Workenhe, S., Kibenge, M.J.T. 2012. Countermeasures against viral disease of farmed fish. Antiviral Research 95, 257-281. 
Kristoffersen, A.B., Rees, E.E., Stryhn, H., Ibarra, R., Campisto, J.-L., Revie, C.W., St-Hilaire, S. 2013. Understanding sources of sea lice for salmon farms in Chile. Preventive Veterinary Medicine 111, 165-175.

Lyngstad, T.M., Hjortaas, M., Kristoffersen, A., Markussen, T., Karlsen, E., Jonassen, C., Jansen, P., 2011. Use of molecular epidemiology to trace transmission pathways for infectious salmon anaemia virus (ISAV) in Norwegian salmon farming. Epidemics 3, 111.

Mardones, F.O., Perez, A.M., Carpenter, T.E. 2009. Epidemiologic investigation of the reemergence of infectious salmon anemia virus in Chile. Diseases of Aquatic Organisms $84,105-114$.

Mardones, F.O., Martinez-Lopez, B., Valdes-Donoso, P., Carpenter, T.E., Perez, A.M. 2014. The role of fish movements and the spread of infectious salmon anemia virus (ISAV) in Chile, 2007-2009. Preventive Veterinary Medicine 114, 37-46.

Marshall et al. 2014. Bona fide evidence for natural vertical transmission of infectious salmon anemia virus in freshwater brood stocks of farmed Atlantic salmon (Salmo salar) in Southern Chile. Journal of Virology 88, 6012-6018.

Miranda, P., Matus V., Olmos, P., Schulze, F. 2012. Evaluación y seguimiento de la situación sanitaria de especies silvestres en agua dulce y mar. Monografía. Asesoría Integral para la pesca y acuicultura, Subsecretaria de Pesca y Acuicultura e Instituto de Fomento Pesquero IFOP. Chile. http://biblioteca.ifop.cl/F 
610

611

612

613

614

615

616

617

618

619

620

621

622

623

624

625

626

627

628

629

630

Murray, A.G., Smith, R.J., Stagg, R.M. 2002. Shipping and the spread of infectious salmon anemia in Scottish aquaculture. Emerging Infect Dis 8, 1-5.

Murray, A.G., Munro, L.A., Wallace, I.S., Berx, B., Pendrey, D., Fraser, D., Raynard, R.S. 2010. Epidemiological investigation into the re-emergence and control of an outbreak of infectious salmon anaemia in the Shetland Islands, Scotland. Diseases of Aquatic Organisms 91, 189-200.

Nylund, A., Devold, M., Plarre, H., Isdal, E., Aarseth, M. 2003. Emergence and maintenance of infectious salmon anaemia virus (ISAV) in Europe: a new hypothesis. Diseases of Aquatic Organisms 56, 11-24.

Olivares G.R., Sepulveda, H.H., Yannicelli, B. 2015. Definition of sanitary boundaries to prevent ISAV spread between salmon farms in Southern Chile based on numerical simulations of currents. Estuarine, Coastal and Shelf Science 158, 31-39.

Olmos, P., Schulze, F. 2013. Evaluación y seguimiento de la situación sanitaria de especies silvestres en agua dulce y mar. Monografía. Asesoría Integral para la pesca y acuicultura, Subsecretaria de Pesca y Acuicultura e Instituto de Fomento Pesquero IFOP. Chile. http://biblioteca.ifop.cl/F

Peeler, E.J., Taylor, N.G.H. 2011. The application of epidemiology in aquatic animal health opportunities and challenges. Veterinary Research 42, 94-109.

Rees, E.E., Ibarra., R., Medina, M., Sanchez, J., Jakob, E., Vanderstichel, R., St-Hilaire, S. 2014. Transmission of Piscirickettsia salmonis among salt water salmonid farms in Chile. Aquaculture 428-429, 180-194. 
631 Rimstad, E., Mjaaland, S. 2002. Infectious salmon anaemia virus: An orthomyxovirus causing

632

633

634

635

636

637

638

639

640

641

642

643

644

645

646

647

648

649

650

651

652 an emerging infection in Atlantic salmon. Acta Pathologica, Microbiologica et Immunologica Scandinavica (APMIS) 110, 273-282.

Rimstad, E. 2011. Examples of emerging virus diseases in salmonid aquaculture. Aquaculture Research 42, 86-89.

Rosenfeld, C., Enríquez, R., Romero, A., Leal, C., González, M., Rolack., H., Molina, S .2009. Determinación de prevalencia de los virus de la Anemia Infecciosa del Salmón (ISA) y de la Enfermedad Pancreática (PD), en la población de peces silvestres y asilvestrados de la Región de La Araucanía, De Los Ríos, De Los Lagos, Aysén y Magallanes con concesiones de salmonicultura. Servicio Nacional de Pesca. Chile. Informe del estudio. Secretaria de Pesca y Acuicultura y Sernapesca. www.bcn.cl/obtienearchivo?id=documentos/10221.../Informe...UACh.

Rosenfeld, C., Doddis, J., Gustafson, L., Remmenga, M., Antognoli, MC., Johnson, C., Gallardo, A., Lara, M., Sandoval, O., Ibarra, R., Henriquez, R. 2015. Spreading factors in Infectious Salmon Anemia virus (ISA) outbreak in southern Chile. ISVEE Meeting November 3-7 Merida, Mexico.

Salama, N.K.G., Rabe, B. 2013. Developing models for investigating the environmental transmission of disease-causing agents within open-cage salmon aquaculture. Aquaculture Environment Interactions 4, 91-115.

Scheel, I., Aldrin, M., Frigessi, A., Jansen, P.A. 2007. A stochastic model for infectious salmon anemia (ISA) in Atlantic salmon farming. Journal of the Royal Society Interface 4, 699706. 
657

658

659

660

661

662

663

664

665

666

667

668

669

670

671

672

673

Sernapesca. 2001 D.S. N 319 de 2001 Reglamento de medidas de protección, control y erradicación de enfermedades de alto riesgo para las especies hidrobiológicas. (Actualizado D.S. No 4 de 2013). Ed by C. National Fisheries Service. http://www.subpesca.cl/institucional/602/w3-propertyvalue-50853.html

Snow, M, McKay, P., McBeath, A.J.A., Black, J., Doig, F., Kerr, R., Cunningham, C.O., Nylund, A., Devoid, M. 2006. Development, application and validation of a Taqman real-time RT-PCR assay for the detection of infectious salmon anaemia virus (ISAV) in Atlantic salmon (Salmo salar). Dev. Biol. Standardization 126: 133-145.

Stene, A., Viljugrein, H., Yndestad, H., Tavornpanich, S., Skjerve, E., 2014. Transmission dynamics of pancreas disease (PD) in a Norwegian fjord: aspects of water transport, contact networks and infection pressure among salmon farms. Journal of Fish Diseases 37, 123-134.

Thorud, K., Djupvik, H.O. 1998. Infectious salmon anaemia in Atlantic slmon (Salmo salar L.). Bull Eur Assoc Fish Pathol 8, 109-111.

USDA APHIS Veterinary Services, Maine Department of Marine Resources, Maine Aquaculture Association. 2010. Infectious Salmon Anemia Program Standards. http://www.aphis.usda.gov/animal_health/animal_dis_spec/aquaculture/downloads/isa_st andards.pdf. 59 pp. Accessed 10 Feb 2015.

Valdes-Donoso, P., Mardones, F.O., Jarpa, M., Ulloa, M., Carpenter, T.E., Perez, A.M. 2013. Co-infection patterns of infectious salmon anaemia and sea lice in farmed Atlantic 
674

675

676

677

678

679

680

681

682

683

684

685

salmon, Salmo salar L., in southern Chile (2007-2009). Journal of Fish Diseases 36, 353-360.

Vanderstichel, R., St-Hilaire, S., Ibarra, R., Lyngstad, T.M., Rees, E., Medina, M.H. 2015. Space-time cluster analysis of the non-pathogenic infectious salmon anemia virus (HPR0 ISAV) in Chile, 2011-2012. Aquaculture 437, 120-126.

Vike, S., Nylund, S., Nylund, A., 2009. ISA virus in Chile: evidence of vertical transmission. Arch Virol 154, 1-8.

Vike, S., Duesund, H., Andersen, L., Nylund, A. 2014. Release and survival of infectious salmon anaemia (ISA) virus during decomposition of Atlantic salmon (Salmo salar L.). Aquaculture, 420-421, 119-125.

686 
Table 1: Results of HPRv univariate analyses for Region de los Lagos and Region Aysén. Lags describe the interval (number of months) between the predicted outcome (HPRv incidence) and the measurement of the predictive variable. For example, significant $p$ values for sea lice lags 0,3 and 5 denotes that HPRv incidence in a given month correlates with sea lice counts in the same month, as well as 3 and 5 months prior. Sea lice measures were only available for a portion of the dataset.

\begin{tabular}{|c|c|c|c|c|}
\hline Region & Variable & $\begin{array}{c}\text { Most predictive lags } \\
(p \leq 0.001)\end{array}$ & $\begin{array}{c}\text { Less predictive lags } \\
(0.001<p \leq 0.05)\end{array}$ & $\begin{array}{c}\text { Non-significant lags } \\
(p>0.05)\end{array}$ \\
\hline \multirow[t]{11}{*}{ Lagos } & Prior HPRv & $1,2,3$ & 4,5 & \\
\hline & Prior HPRO & & & $0,1,2,3,4,5$ \\
\hline & Sea lice & 0 & 3,5 & $1,2,4$ \\
\hline & Susceptible sites & $0,1,2,3,4,5$ & & \\
\hline & Fish per hectare ${ }^{1}$ & $0,1,2,3,4,5$ & & \\
\hline & Fish kg per hectare ${ }^{2}$ & $0,1,2,3,4,5$ & & \\
\hline & HPRv in 'fish supplier' areas & 1,4 & $1,2,5$ & 0,3 \\
\hline & HPRv in 'port user' areas & $0,1,2,3,4,5$ & & \\
\hline & HPRv in 'acopio user' areas & $0,1,2,3,4,5$ & & \\
\hline & HPRv in 'plant user' areas & $0,1,2,3,4,5$ & & \\
\hline & HPRv in 'neighbor' areas & $0,1,2,3,4$ & & 5 \\
\hline \multirow[t]{11}{*}{ Aysén } & Prior HPRv & $1,2,3,4$ & & 5 \\
\hline & Prior HPRO & & & $0,1,2,3,4,5$ \\
\hline & Sea lice & 0 & 3,5 & $1,2,4$ \\
\hline & Susceptible sites & $0,1,2,3,4,5$ & & \\
\hline & Fish per hectare ${ }^{1}$ & $2,3,4,5$ & 1 & 0 \\
\hline & Fish kg per hectare ${ }^{2}$ & $2,3,4,5$ & 0,1 & \\
\hline & HPRv in 'fish supplier' areas & 0 & 3,4 & $1,2,5$ \\
\hline & HPRv in 'port user' areas & & & $0,1,2,3,4,5$ \\
\hline & HPRv in 'acopio user' areas & & 5 & $0,1,2,3,4$ \\
\hline & HPRv in 'plant user' areas & & 5 & $0,1,2,3,4$ \\
\hline & HPRv in 'neighbor' areas & $0,2,4,5$ & 1,3 & \\
\hline
\end{tabular}

${ }^{1}$ Fish per hectare is measured in units of hundred-thousand fish per 5000 hectares.

${ }^{2}$ Fish kg per hectare is measured in units of one million kilogram $(\mathrm{kg})$ of fish per 5000 hectares. 
Table 2: Results of HPRO univariate analyses for Region de los Lagos and Region Aysén. Lags describe the interval (number of months) between the predicted outcome (HPRO incidence) and the measurement of the predictive variable. Sea lice measures were only available for a portion of the dataset.

\begin{tabular}{|c|c|c|c|c|}
\hline Region & Variable & $\begin{array}{c}\text { Most predictive lags } \\
(p \leq 0.001)\end{array}$ & $\begin{array}{c}\text { Less predictive lags } \\
(0.001<\mathrm{p} \leq 0.05)\end{array}$ & $\begin{array}{c}\text { Non-significant lags } \\
(p>0.05)\end{array}$ \\
\hline \multirow[t]{11}{*}{ Lagos } & Prior HPRO & 1 & & $2,3,4,5$ \\
\hline & Prior HPRv & & & $0-37$ \\
\hline & Sea lice & & *insufficient data & \\
\hline & Susceptible sites & $0,1,2,3,4,5$ & & \\
\hline & Fish per hectare ${ }^{3}$ & $0,1,2,3,4,5$ & & \\
\hline & Fish kg per hectare ${ }^{4}$ & $0,1,2,3,4,5$ & & \\
\hline & HPRO in 'fish supplier' areas & 1,4 & 2,5 & 0,3 \\
\hline & HPRO in 'port user' areas & $0,1,2,3,4,5$ & & \\
\hline & HPRO in 'acopio user' areas & $0,1,2,3,4,5$ & & \\
\hline & HPRO in 'plant user' areas & $0,1,2,3,4,5$ & & \\
\hline & HPRO in 'neighbor' areas & $0,1,2,3,4$ & & 5 \\
\hline \multirow[t]{11}{*}{ Aysén } & Prior HPRO & 1 & 2 & $3,4,5$ \\
\hline & Prior HPRv & $30,31,32,33$ & & $0-29,34-37$ \\
\hline & Sea lice & & & $0,1,2,3,4,5$ \\
\hline & Susceptible sites & $0,1,2,3,4,5$ & & \\
\hline & Fish per hectare ${ }^{3}$ & $2,3,4,5$ & 1 & 0 \\
\hline & Fish kg per hectare ${ }^{4}$ & $2,3,4,5$ & 0,1 & \\
\hline & HPRO in 'fish supplier' areas & 0 & 3,4 & $1,2,5$ \\
\hline & HPRO in 'port user' areas & & & $0,1,2,3,4,5$ \\
\hline & HPRO in 'acopio user' areas & & 5 & $0,1,2,3,4$ \\
\hline & HPRO in 'plant user' areas & & 5 & $0,1,2,3,4$ \\
\hline & HPRO in 'neighbor' areas & $0,2,4,5$ & 1,3 & \\
\hline
\end{tabular}

\footnotetext{
${ }^{3}$ Fish per hectare is measured in units of hundred-thousand fish per 5000 hectares.

${ }^{4}$ Fish kg per hectare is measured in units of one million kilogram $(\mathrm{kg})$ of fish per 5000 hectares.
} 
Table 3: Pearson correlation coefficients for the full HPRv study period (67 months, 56 areas, $n=3752$ ), and the HPR0 study (35 months, 56 areas, $\mathrm{n}=1960)$. Predictive variables for HPRv measure HPRv incidence in the described contact network; and predictive variables for HPRO measure HPRO incidence in the described contact network. Asterisks indicate statistically significant relationships $(p<0.001)$. Plant stands for processing plant.

\begin{tabular}{lllllll}
\hline Study & Predictors & Processing plant user & Acopio user & Port user & Fish supplier & Neighbor \\
\hline HPRv & Plant user & 1.0 & & & & \\
& Acopio user & $0.9749^{*}$ & 1.0 & & & \\
& Port user & $0.6721^{*}$ & $0.7252^{*}$ & 1.0 & & \\
& Fish supplier & $0.0600^{*}$ & $0.0567^{*}$ & $0.0823^{*}$ & 1.0 & \\
& Neighbors & $0.3209^{*}$ & $0.3238^{*}$ & $0.2924^{*}$ & $0.2516^{*}$ & 1.0 \\
\hline HPRO & Plant user & 1.0 & & & & \\
& Acopio user & $0.9505^{*}$ & 1.0 & & & \\
& Port user & $0.6735^{*}$ & $0.7261^{*}$ & 1.0 & & \\
& Fish supplier & -0.0054 & -0.0056 & -0.0050 & 1.0 & \\
& Neighbors & $0.1432^{*}$ & $0.1540^{*}$ & $0.1103^{*}$ & -0.0101 & 1.0 \\
\hline
\end{tabular}

Table 4: Multiple regression model for spatio-temporal incidence of ISAV HPRv in Region de los Lagos and Region Aysén. Variables describe characteristics (susceptible sites) or HPRv counts (prior HPRv) in the area in question, or the sum of HPRv counts in its described contact network (port user, fish supplier, neighbor). Fitted lag describes which month or combination of months was most predictive and thus represented in the model. Sum areas refers to total HPRv counts across areas in a contact network. Region de los Lagos model $R$ square $=0.3081$, adjusted $R$ square $=0.3056$, CS (cross sections, number of areas) $=21$, $T S$ (time series, number of months) $=67$. Region Aysén model $R$ square $=0.1570$, adjusted $R$ square $=0.1556, C S=35, T S=67$.

\begin{tabular}{|c|c|c|c|c|c|c|}
\hline Region & Predictors & Estimate & Standard Error & t value & $p$ value & Fitted lag \\
\hline \multirow[t]{6}{*}{ Lagos } & Intercept & -0.0254 & 0.0124 & -2.05 & 0.0410 & \\
\hline & Prior HPRv & 0.1258 & 0.0124 & 10.88 & $<0.0001$ & Sum, 0-3 months prior \\
\hline & Port user & 0.0243 & 0.00396 & 6.14 & $<0.0001$ & Sum areas, 2 months prior \\
\hline & Susceptible sites & 0.0152 & 0.00244 & 6.21 & $<0.0001$ & Number, 3 month prior \\
\hline & Fish supplier & 0.0378 & 0.0143 & 2.64 & 0.0084 & Sum areas, 1 month prior \\
\hline & Neighbors & 0.0137 & 0.00622 & 2.20 & 0.0278 & Sum area, 0-1 month prior \\
\hline \multirow[t]{5}{*}{ Aysén } & Intercept & -0.0176 & 0.00884 & -1.99 & 0.0462 & \\
\hline & Prior HPRv & 0.0564 & 0.0101 & 5.58 & $<0.0001$ & Sum, 0-3 months prior \\
\hline & Fish supplier & 2.1843 & 0.1594 & 13.70 & 0.0084 & Sum areas, current month \\
\hline & Susceptible sites & 0.0140 & 0.00162 & 8.63 & $<0.0001$ & Number, 3 months prior \\
\hline & Neighbors & 0.0247 & 0.00507 & 4.87 & $<0.0001$ & Sum areas, 0-2 months prior \\
\hline
\end{tabular}


Table 5: Multiple regression model for spatio-temporal incidence of ISAV HPRv in Region de los Lagos and Region Aysén before April 2009. Variables describe characteristics (susceptible sites) or HPRv counts (prior HPRv) in the area in question, or the sum of HPRv counts in its contact network (remaining variables). Fitted lag describes which month or combination of months was most predictive and thus represented in the model. Sum areas refers to the sum of HPRv counts across areas in a contact network. Region de los Lago model $R$ square $=0.2400$, adjusted $R$ square $=0.2350$, CS (cross sections, number of areas) $=21, T S$ (time series, number of months) $=22$. Region Aysén model $R$ square $=0.2092$, adjusted $R$ square $=0.2051, C S=35, T S=22$.

\begin{tabular}{llccccc}
\hline Region & Predictor & Estimate & Standard Error & t value & p value & Fitted lag \\
\hline Lagos & Intercept & -0.0901 & 0.0540 & -1.67 & 0.0958 & \\
& Prior HPRv & 0.1446 & 0.0193 & 7.51 & $<0.0001$ & Sum, 0-3 months prior \\
& Susceptible sites & 0.0307 & 0.00501 & 6.12 & $<0.0001$ & Number, current month \\
& Neighbors & 0.0381 & 0.0195 & 1.95 & 0.0514 & Sum areas, 1 month prior \\
\hline Aysén & Intercept & -0.0143 & 0.0282 & -0.51 & 0.6107 & \\
& Prior HPRv & 0.0372 & 0.0175 & 2.13 & 0.0337 & Sum, 0-3 months prior \\
& Fish suppliers & 3.5191 & 0.3566 & 9.87 & $<0.0001$ & Sum areas, current month \\
& Susceptible sites & 0.0188 & 0.0033 & 5.69 & $<0.0001$ & Number, 1 month prior \\
& Neighbors & 0.1168 & 0.0264 & 4.43 & $<0.0001$ & Sum areas, 4 months prior \\
\hline
\end{tabular}

Table 6: Multiple regression model for spatio-temporal incidence of ISAV HPRV in combined regions in the period starting April 2009. Variables describe characteristics (susceptible sites) or ISAV counts (prior HPRV, prior HPRO) in the area in question, or the sum of HPRv counts in its contact network (remaining variables). Sum areas refers to the sum of HPRv counts across areas in a contact network. Fitted lag describes which month or combination of months was most predictive and thus represented in the model. Model $R$ square $=0.0792$, adjusted $R$ square $=0.0770$, CS (cross sections, number of areas) $=56, T S$ (time series, number of months) $=45$.

\begin{tabular}{lccccc}
\hline Variable & Estimate & Standard Error & t value & $\boldsymbol{p}$ value & Fitted lag \\
\hline Intercept & -0.0039 & 0.00405 & -0.96 & 0.3393 & \\
Prior HPRv & 0.0591 & 0.0107 & 5.52 & $<0.0001$ & Number, 4 months prior \\
Susceptible sites & 0.0066 & 0.00098 & 6.69 & $<0.0001$ & Number, 5 months prior \\
Fish suppliers & 0.9541 & 0.1075 & 8.87 & $<0.0001$ & Sum areas, current month \\
Port users & 0.1075 & 0.0227 & 4.74 & $<0.0001$ & Sum areas, 1 month prior \\
Acopio users & -0.0415 & 0.0130 & -3.20 & 0.0014 & Sum areas, 2 months prior \\
Prior HPRO & -0.0177 & 0.00833 & -2.13 & 0.0335 & Number, 4 months prior \\
\hline
\end{tabular}


Table 7: Multiple regression model for spatio-temporal incidence of ISAV HPRO in combined regions. Variables describe characteristics (susceptible sites, fish per hectare), HPRO incidence (prior HPRO) or HPRv incidence (prior HPRv) in the area in question or HPRO incidence in its contact areas (remaining variables). Fitted lag describes which month or combination of months was most predictive and thus represented in the model. Sum areas refers to the sum of HPRO counts across areas in a contact network. Model $R$ square $=0.1183$, adjusted $R$ square $=0.1156, C S$ (cross sections, number of areas) $=56, T S$ (time series, number of months) $=35$.

\begin{tabular}{lccccc}
\hline Variable & Estimate & Standard Error & t value & p value & Fitted lag \\
\hline Intercept & -0.0338 & 0.0112 & -3.02 & 0.0026 & \\
Prior HPRO & 0.1554 & 0.0225 & 6.90 & $<0.0001$ & Sum, 1 month prior \\
Prior HPRv & 0.0605 & 0.0156 & 3.88 & 0.0001 & Sum, 31 months prior \\
Susceptible sites & 0.0217 & 0.00339 & 6.39 & $<0.0001$ & Average, 0-3 months prior \\
Neighbors & 0.0456 & 0.0125 & 3.65 & 0.0003 & Sum areas, 1 month prior \\
Fish per hectare $^{5}$ & 0.0020 & 0.00059 & 3.46 & 0.0006 & Number, 2 months prior \\
Port users & 0.0417 & 0.0177 & 2.35 & 0.0188 & Sum areas, current month \\
\hline
\end{tabular}

Table 8: Individual area analysis, showing the proportion of areas with repeated associations between ISAV status and identified predictors. Predictors include live fish transfers for grow-out (transfers), shared water systems (neighbors) or shared ports (ports). Results are grouped by variable, though the evaluated lag may vary by Region and ISAV type. For example, 'transfers' for HPRv sums the number of areas where this variable was predictive. Sums include areas in either Region de los Lagos or Region Aysén, though the TSCS-identified lag was 'last month' for the former and 'this month' for latter Region.

\begin{tabular}{cccc}
\hline & $\begin{array}{c}\text { Proportion, transfers } \\
\mathbf{p}<0.05\end{array}$ & $\begin{array}{c}\text { Proportion, neighbors } \\
\mathbf{p}<\mathbf{0 . 0 5}\end{array}$ & $\begin{array}{c}\text { Proportion, ports } \\
\mathbf{p}<0.05\end{array}$ \\
\hline HPRv & $5 / 11$ & $19 / 44$ & $2 / 7$ \\
HPRO & - & $13 / 41$ & $1 / 7$ \\
\hline
\end{tabular}

\footnotetext{
${ }^{5}$ Fish per hectare is measured in units of hundred-thousand fish per 5000 hectares.
} 


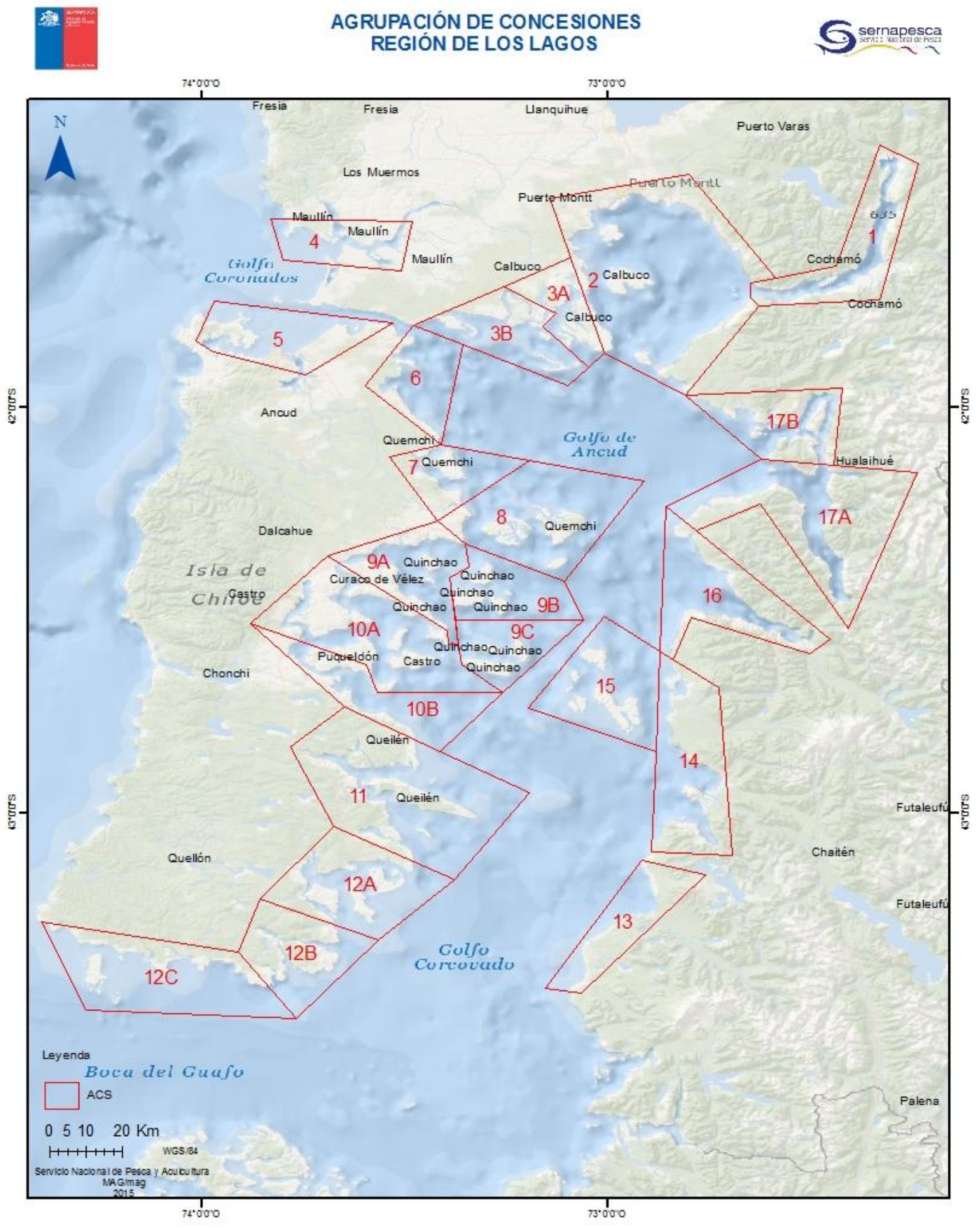

Figure 1: Map of Region de los Lagos in Chile. Numbered polygons correspond to management areas (also known as barrios). 


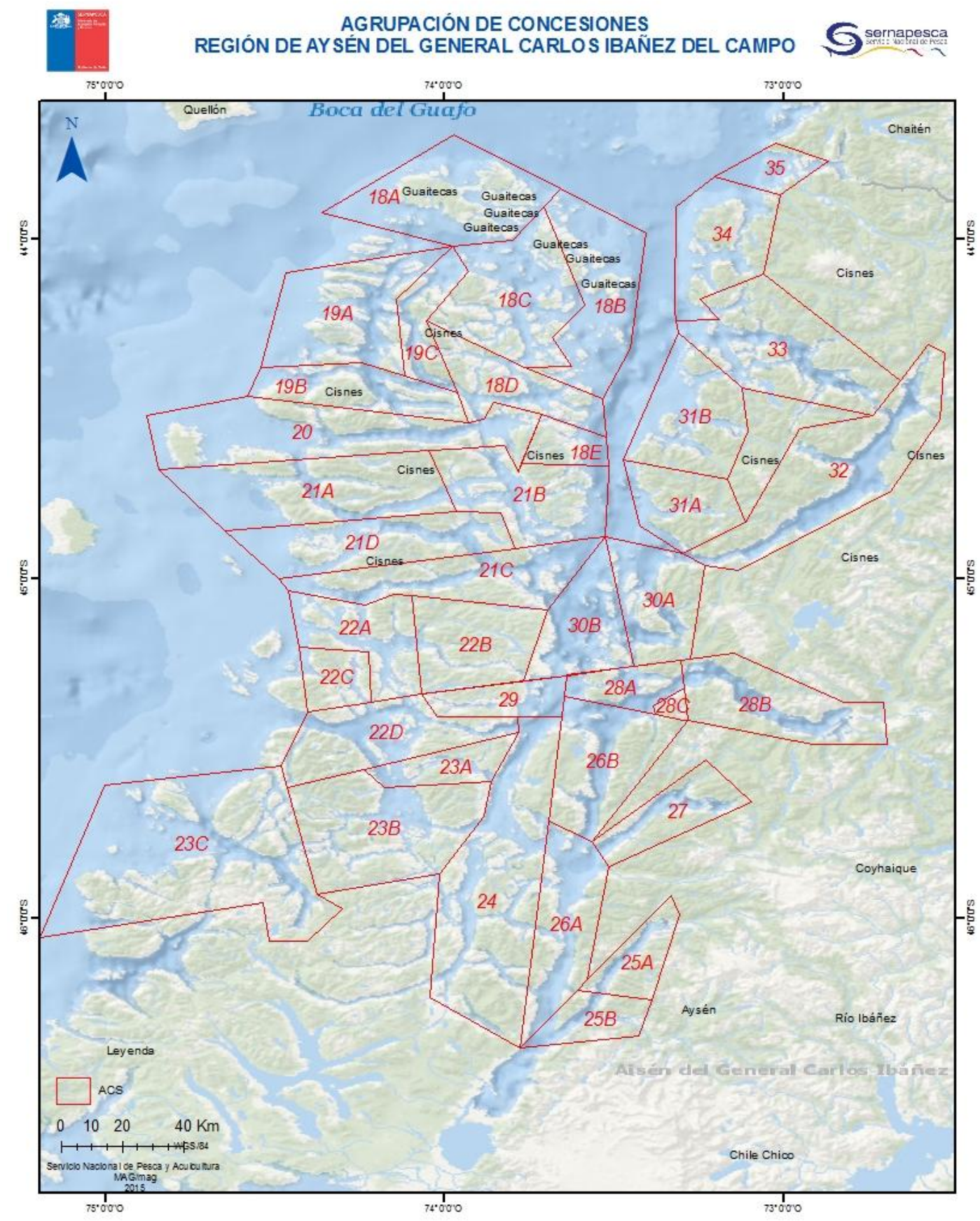

Figure 2: Map of Region Aysén in Chile. Numbered polygons correspond to management areas (also known as barrios). 


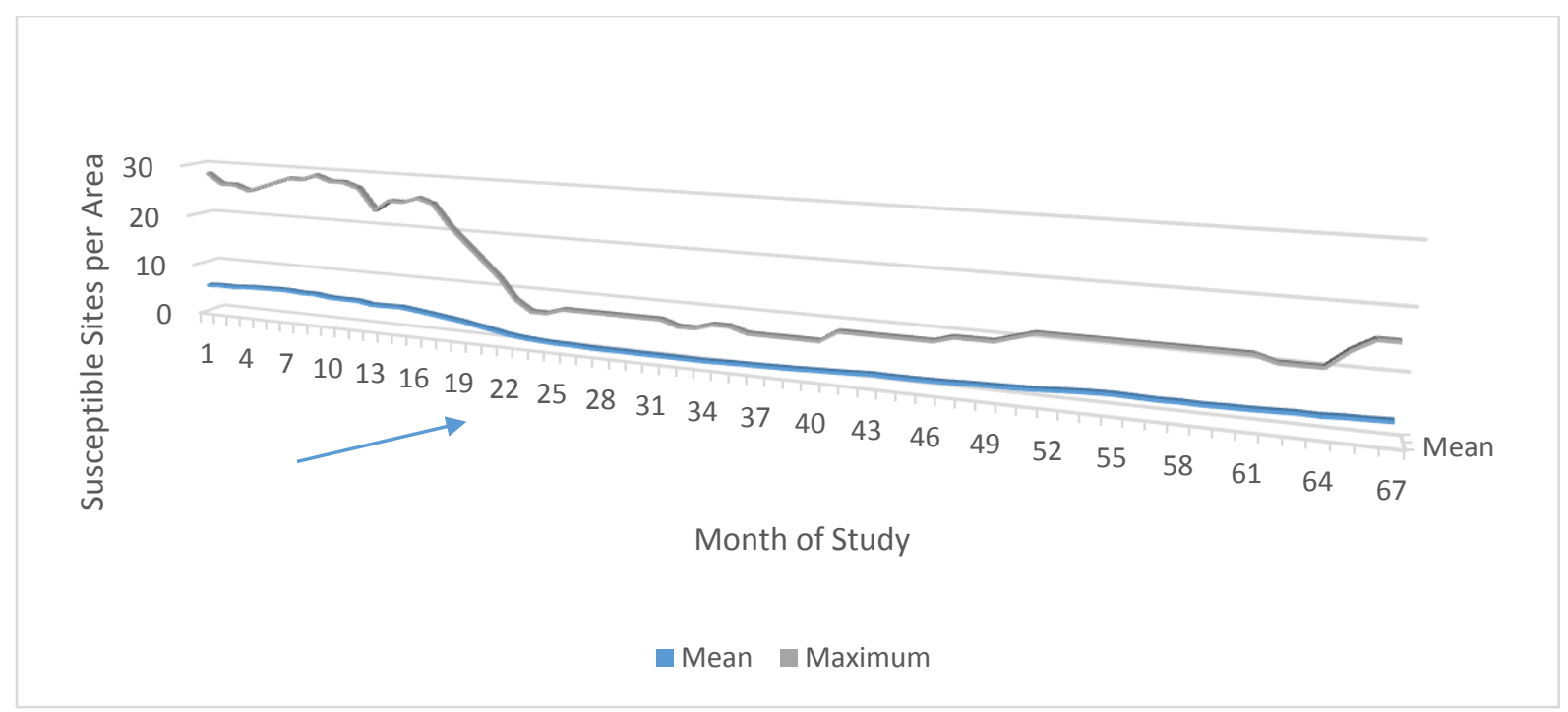

Figure 3: Susceptible sites per area, by month. Mean and maximum number of active sites farming ATS in a given month calculated over 56 areas. A mean of 5 for a particular month suggests a total of $56 \times 5$ ATS farms were in operation in Chile's Regions de los Lagos and Aysen during that month of the study period. The arrow points to the date of revised sanitary regulations (March 2009). Minimum values, not charted, were typically zero.

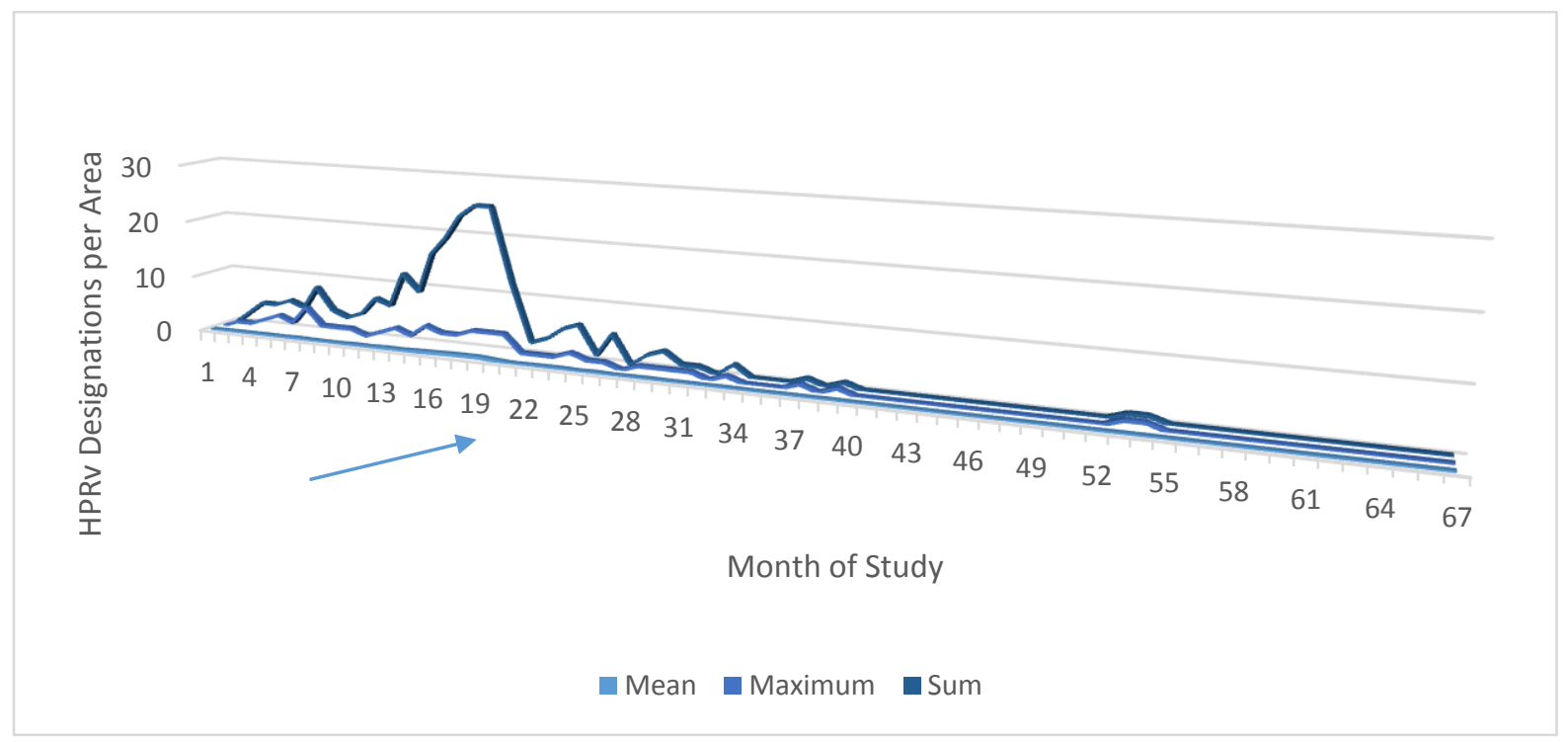

Figure 4: Area ISAV HPRv designations by month. Mean, maximum and sum of designations, by month, across the 56 management areas in Chile's Regions de los Lagos and Aysen. Month 1 corresponds to June 2007. Month 67 corresponds to December 2012. The arrow points to the date of revised sanitary regulations (March 2009). Minimum values, not charted, were typically zero. 


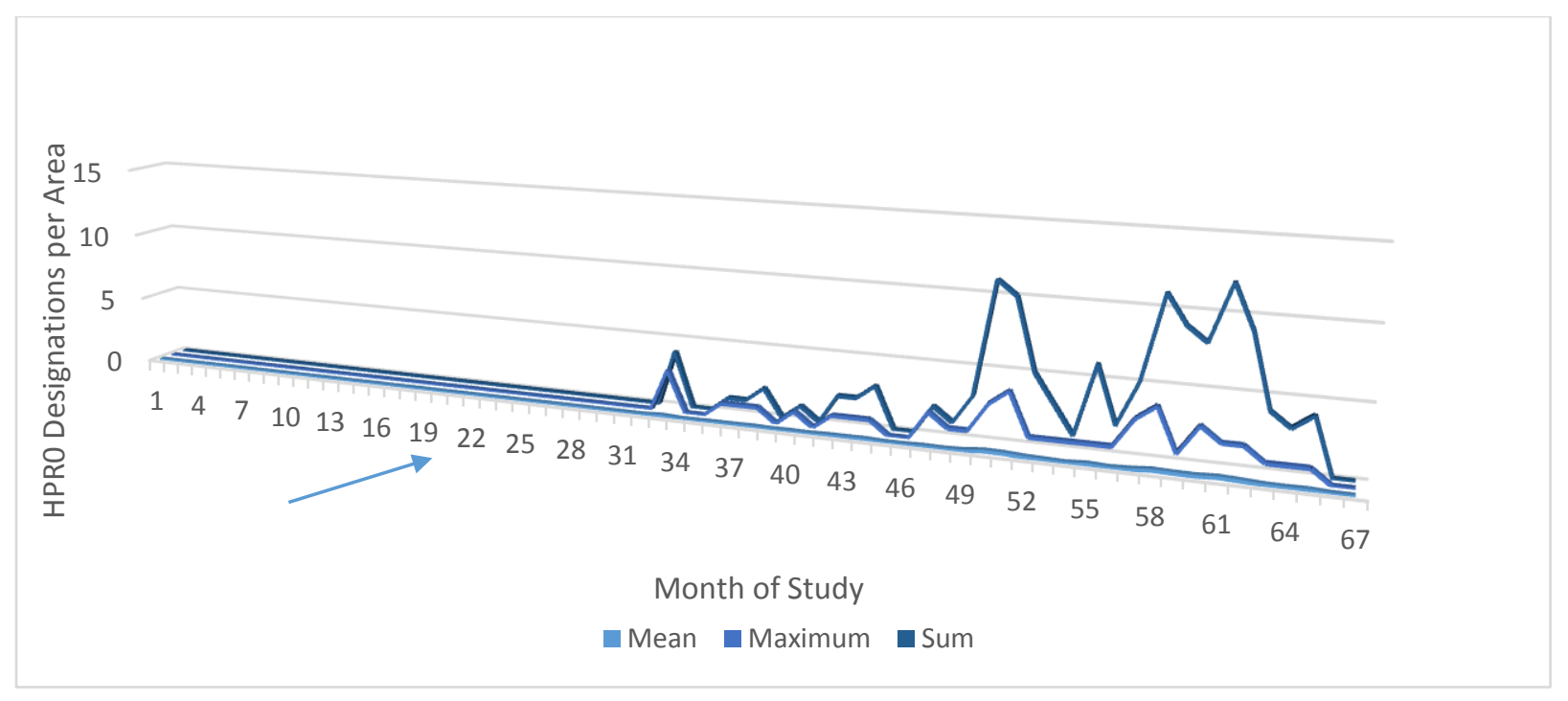

Figure 5: Area ISAV HPRO designations by month. Mean, maximum and sum of designations, by month, across the 56 management areas in Chile's Regions de los Lagos and Aysen. Month 1 corresponds to June 2007. Month 67 corresponds to December 2012. The arrow points to the date of revised sanitary regulations (March 2009). Minimum values, not charted, were typically zero. 